This article is licensed under the Creative Commons Attribution-NonCommercial 4.0 International License (CC BY-NC) (http://www.karger.com/Services/OpenAccessLicense). Usage and distribution for commercial purposes requires written permission.

\title{
Acute Intravenous Calcium Antagonist for Suspected Hemiplegic Migraine - A Case Story
}

\author{
Charlotte Lützhøft Rath $^{\mathrm{a}} \quad$ Jun He $\mathrm{H}^{\mathrm{a}}$ Mette Maria Nordling ${ }^{\mathrm{b}}$ \\ Troels Wienecke ${ }^{a}$ \\ ${ }^{a}$ Department of Neurology, Zealand University Hospital, Roskilde, Denmark; \\ ${ }^{\mathrm{b}}$ Department of Radiology, Research Center for Advanced Imaging, Zealand University \\ Hospital, Roskilde, Denmark
}

\section{Keywords}

Hemiplegic migraine - Calcium antagonist - Acute stroke evaluation - Stroke mimics - Acute ischemic stroke $\cdot$ iv-rtPA

\begin{abstract}
Stroke mimics, like attacks of hemiplegic migraine, are challenging in acute stroke evaluation. We present a 28-year-old woman with a suspected hemiplegic migraine attack with leftsided hemiparalysis. Brain CT with perfusion imaging $1 \mathrm{~h} 54$ min after symptom onset revealed hypoperfusion in the right hemisphere. The patient was treated with intravenous recombinant tissue plasminogen activator (rtPA) with no effect. After a subsequent intravenous verapamil infusion, the patient gained full motor function within 10 min. Brain magnetic resonance imaging (MRI) performed $5 \mathrm{~h} 46 \mathrm{~min}$ after symptom onset revealed diffusion restriction in the same area as the hypoperfusion on CT. There were no notable changes on T2 images. The patient stayed clinically in remission, except for reduced sensation for all modalities on the extremities on the left side. Although brain CT $24 \mathrm{~h}$ after symptom onset revealed an edema in the same area, an MRI performed 17 days later showed no new infarctions.
\end{abstract}




\section{Case Reports in Neurology}

Case Rep Neurol 2017;9:98-105

DOI: $10.1159 / 000474934$

(C) 2017 The Author(s). Published by S. Karger AG, Basel www.karger.com/crn

Rath et al.: Acute Intravenous Calcium Antagonist for Suspected Hemiplegic Migraine A Case Story

Young patients with a history of migraine with aura admitted with symptoms of acute ischemic stroke are at risk of insufficient treatment. Calcium antagonists might be considered if there is no effect of first-line treatment with rtPA.

(C) 2017 The Author(s)

Published by S. Karger AG, Basel

\section{Introduction}

Stroke mimics account for $14 \%$ of all suspected stroke presentations in the TIA (transient ischemic attack) Unit or Stroke Unit [1]. Seizures, syncope, sepsis, primary headache disorders, and non-organic presentations are the most common stroke mimics [1]. Previous studies have shown an association between migraine and ischemic stroke, and separating hemiplegic migraine attacks from ischemic stroke is often challenging in acute stroke evaluation [2].

Sporadic hemiplegic migraine is a rare type of migraine with a motor aura phase of $<72 \mathrm{~h}$ [3], but patients frequently experience prolonged aura symptoms [4], and patients with permanent symptoms have been reported [5].

We present a patient with hemiplegic migraine who received recombinant tissue plasminogen activator (rtPA) and intravenous calcium antagonists.

\section{Case Presentation}

Our patient is a 28-year-old non-smoking woman with a history of 13 attacks of hemiplegic migraine since the age of 19 years. Usually, the attacks gradually worsen for a few minutes and disappear after 1-2 h when headache sets in. Some hemiplegic symptoms last a few days; but on rare occasions, she has experienced hemiplegia for several months. Over the years, she has suffered from several cerebral ischemic attacks due to her hemiplegic migraine. In recent times, there has been a tendency towards worse attacks with more severe and prolonged hemiplegia and dysarthria. Her father suffers from cluster headache, but otherwise there is no family history of neurological or cardiovascular disease. She was surgically treated for a patent foramen ovale 7 years earlier. Different prophylactic treatment regimens including topiramat, candesartan, and pregabalin have not had a diminishing effect on either frequency or severity of attacks.

Her only risk factor for ischemic stroke is a high total cholesterol level $(8.4 \mathrm{mmol} / \mathrm{L})$ treated with ezetimibe. She has never had antiplatelet therapy because her hemiplegic attacks have always been perceived as hemiplegic migraine attacks.

Previous extensive genetic diagnostic work-up included exclusion of MERRF, NARP, Fabry disease, MELAS, and mutations in CACNA1A, ATP1A2, ATP1A3, NOTCH3, POLG, PRRT2, SCN1A, SLC1A3, and SLC2A1. All results were found normal.

On the day of admission, the patient had a usual attack with sudden onset of slurred speech, left-sided blurred vision, numbness, and weakness of her left arm and leg. The symptoms progressed over a few minutes and reached a severity of hemiplegia worse than usual. The patient called an ambulance and was immediately referred to the Stroke Unit. 


\section{Case Reports in Neurology}

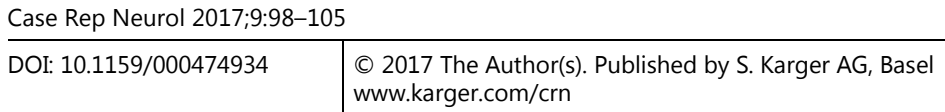

Rath et al.: Acute Intravenous Calcium Antagonist for Suspected Hemiplegic Migraine A Case Story

On admission, $1 \mathrm{~h} 40 \mathrm{~min}$ after symptom onset (Table 1), the patient was alert and cooperative but complained of inability to move her left arm and leg. She did not suffer from a headache.

Physical examination revealed dysarthria, left-sided hemianopia and central facial palsy, and paralysis in her left arm and leg (Medical Research Council grade 1/5). She had a National Institute of Health Stroke Scale (NIHSS) score of 13. A brain CT with perfusion imaging performed $1 \mathrm{~h} 54$ min after symptom onset revealed a prolonged mean transit time (MTT), i.e., a hypoperfusion in the right frontal lobe reaching to the parietal lobe (Fig. 1a, b). There were also signs of multiple older infarctions in both hemispheres - the right occipital lobe, the left frontal and occipital lobe, and on the left side of the cerebellum.

The patient was treated with $0.9 \mathrm{mg} / \mathrm{kg}$ intravenous rtPA $2 \mathrm{~h} 11$ min after symptom onset. After 54 min of rtPA infusion, there was but a slight effect, and the patient was able to move the fingers of her left hand. There was no further improvement.

Then, $0.1 \mathrm{mg} / \mathrm{kg}$ intravenous verapamil as a 20-min infusion was administered $4 \mathrm{~h} 43$ min after symptom onset. The patient gained full motor function within $10 \mathrm{~min}$. Brain magnetic resonance imaging (MRI) performed 5 h 46 min after symptom onset (Fig. 1c, d) revealed diffusion restriction (Fig. 1c) in the same area as the hypoperfusion on CT (Fig. 1b). There were no notable changes on $\mathrm{T} 2$ images (Fig. 1d). The patient stayed fully recovered, except for reduced sensation for all modalities on the extremities on the left side.

A new brain CT $24 \mathrm{~h}$ after symptom onset revealed an edema in the same area as the hypoperfusion seen on the perfusion images at admission (Fig. 2). An MRI performed 17 days later showed no new infarctions (Fig. 3).

\section{Discussion}

To the best of our knowledge, this is the fourth case to report efficacy using an intravenous calcium channel blocker for the acute treatment of a hemiplegic migraine attack. Of the 3 previous reports, 2 showed resolution of hemiplegia [6, 7]. In the third case, the patient had resolution of headache but persistent hemiparesis [8].

Migraine headache with aura is associated with a 2 -fold increased risk of ischemic stroke in women under the age of 45 years [2]. A history of headache is often neglected in the acute evaluation of stroke patients, but it is especially important in younger patients without traditional risk factors for ischemic stroke [9]. Patients with migraine misdiagnosed as stroke as well as patients with stroke misdiagnosed as migraine are both at risk of missing a potentially effective treatment.

In our patient, it is impossible to differentiate whether the patient recovered from the intravenous rtPA, the intravenous verapamil, or experienced a spontaneous recovery. However, this is the third reported case of suspected hemiplegic migraine where the patient regained full motor function during verapamil infusion $[6,7]$. At the time of verapamil infusion, $1 \mathrm{~h} 32 \mathrm{~min}$ had elapsed since the end of rtPA infusion - with no remarkable gain of motor function.

It is impossible to tell whether this patient suffered from a stroke or had an attack of hemiplegic migraine. The sudden onset of symptoms, previous infarctions on the brain CT, DWI lesions in the acute phase, and the permanently reduced sensation in the affected limbs 


\section{Case Reports in Neurology}

Case Rep Neurol 2017;9:98-105

DOI: $10.1159 / 000474934$

(C) 2017 The Author(s). Published by S. Karger AG, Basel www.karger.com/crn

Rath et al:: Acute Intravenous Calcium Antagonist for Suspected Hemiplegic Migraine A Case Story

all point to stroke. On the other hand, the progression of symptoms over several minutes, the convincing effect of intravenous verapamil, and the MRI performed after 17 days with no new infarctions point to hemiplegic migraine attack.

One of the pathophysiological theories about migrainous infarction is the cortical spreading depression (CSD) theory. CSD is a wave of depolarization originating in the occipital lobe spreading forward across the cerebral cortex [10], followed by a reduction in cerebral blood flow. This corresponds to clinical aura symptoms [11] and may in rare cases result in a critically low blood flow and a subsequent ischemic stroke. In some rat models, CSD could not be recorded after perfusing the cortical slices with calcium-free medium or after blocking the calcium channels [12].

Different mutations in genes expressing a calcium channel (CACNA1A) which lead to sporadic and/or familial hemiplegic migraine are known [13]. However, in the majority of patients with hemiplegic migraine, whether familial or sporadic, it is not possible to identify a genetic mutation.

Images taken during the acute phase of hemiplegic migraine attacks show hypoperfusion [14] which could be caused by vasoconstriction, although DWI hyperintense signals do not appear in these cases, which in our case could suggest stroke as the etiology. Verapamil is a calcium antagonist that blocks the L-type calcium channel resulting in a reduced calcium influx. A reduced cellular calcium influx causes reduced vasoconstriction.

The chances of gaining evidence supporting the effect of intravenous verapamil in the treatment of an acute attack of hemiplegic migraine are very low because of the rarity of the disease. Furthermore, changes in genes encoding sodium channels are also known to cause hemiplegic migraine [15], and we cannot expect that these patients will have any effect of treatment with a calcium channel blocker.

Young patients, with a history of migraine, admitted with acute ischemic stroke are at risk of insufficient treatment [16]. In young patients, with acute stroke-like symptoms, with no or few traditional risk factors for ischemic stroke, one should consider treatment with calcium antagonists, if there is no effect of first-line evidence-based treatment with rtPA.

\section{References}

1 Fernandes PM, Whiteley WN, Hart SR, Salman RA-S: Strokes: mimics and chameleons. Pract Neurol 2013;13:21-28.

-2 Spector JT, Kahn SR, Jones MR, Jayakumar M, Dalal D, Nazarian S: Migraine headache and ischemic stroke risk: an updated meta-analysis. Am J Med 2010;123:612-624.

$\checkmark 3$ Headache Classification Committee of the International Headache Society (IHS): The International Classification of Headache Disorders, 3rd edition (beta version). Cephalalgia 2013;33:629-808.

4 Thomsen LL, Ostergaard E, Olesen J, Russell MB: Evidence for a separate type of migraine with aura: sporadic hemiplegic migraine. Neurology 2003;60:595-601.

5 Schwedt TJ, Zhou J, Dodick DW: Sporadic hemiplegic migraine with permanent neurological deficits. Headache 2014;54:163-166.

Yu W, Horowitz SH: Familial hemiplegic migraine and its abortive therapy with intravenous verapamil. Neurology 2001;57:1732-1733.

7 Knierim E: Recurrent stroke due to a novel voltage sensor mutation in a $\mathrm{Ca}_{\mathrm{v}} 2.1$ responds to verapamil. Stroke 2011;42:e14-e17.

-8 Hsu DA: Hemiplegic migraine: hyperperfusion and abortive therapy with intravenous verapamil. Brain Dev 2008;30:86-90. 
Laurell K, Artto V, Bendtsen L, Hagen K, Kallela M, Meyer EL, Putaala J, Tronvik E, Zwart JA, Linde M: Migrainous infarction: a Nordic multicenter study. Eur J Neurol 2011;18:1220-1226.

10 Lauritzen M, Skyhøj Olsen T, Lassen NA, Paulson OB: Changes in regional cerebral blood flow during the course of classic migraine attacks. Ann Neurol 1983;13:633-641. Olesen J, Larsen B, Lauritzen M: Focal hyperemia followed by spreading oligemia and impaired activation of rCBF in classic migraine. Ann Neurol 1981;9:344-352. Jing J, Aitken PG, Somjen GG: Role of calcium channels in spreading depression in rat hippocampal slices. Brain Res 1993;604:251-259. Pietrobon D: CaV2.1 channelopathies. Pflugers Arch 2010;460:375-393.

$>14$ Hansen JM, Schytz HW, Larsen VA, Iversen HK, Ashina M: Hemiplegic migraine aura begins with cerebral hypoperfusion: imaging in the acute phase. Headache 2011;51:1289-1296.

15 Weller CM, Pelzer N, de Vries B, López MA, De Fàbregues O, Pascual J, Arroyo MA, Koelewijn SC, Stam AH, Haan J, Ferrari MD, Terwindt GM, van den Maagdenberg AM: Two novel SCN1A mutations identified in families with familial hemiplegic migraine. Cephalalgia 2014;34:1062-1069.

16 Øygarden H, Elnan Kvistad C, Thomassen L, Waje-Andreassen U, Naess H: Does a history of migraine affect the rate of thrombolysis in young stroke patients? Stroke Res Treat 2013;2013:351064. 


\section{Case Reports in Neurology}

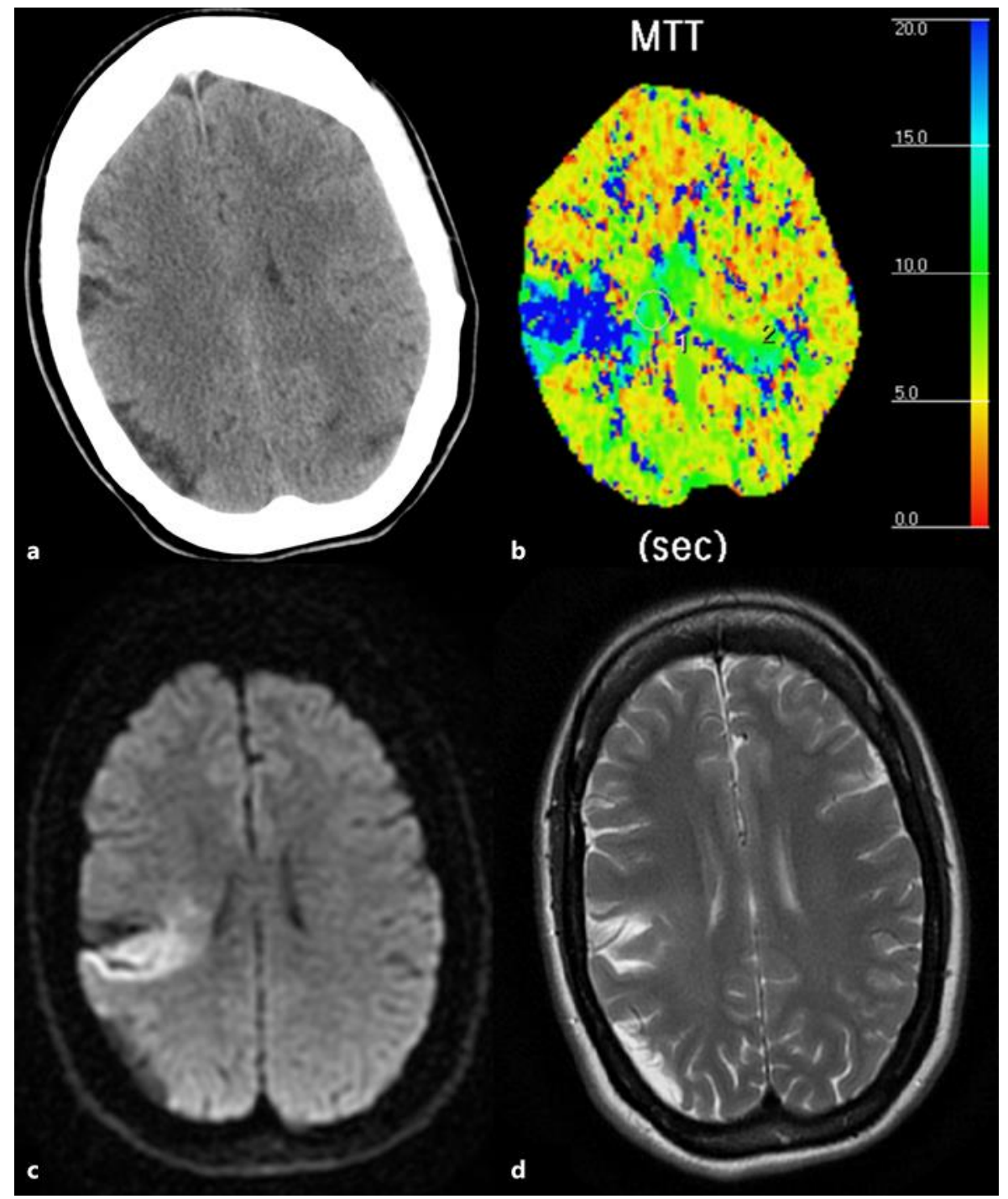

Fig. 1. a Non-contrast brain CT at admission. b CT perfusion MTT at admission. c MR diffusion. d MR T2 axial 5 h 46 min after symptom onset.

(sec) 


\section{Case Reports in Neurology}

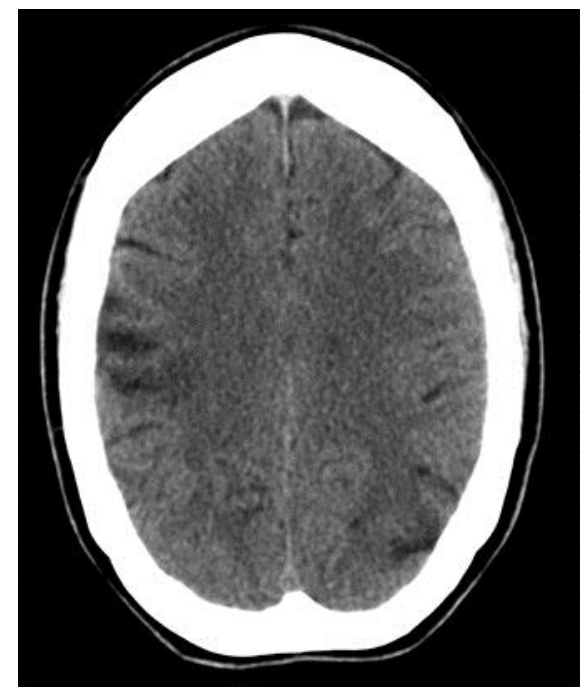

Fig. 2. Non-contrast brain CT $24 \mathrm{~h}$ after symptom onset.

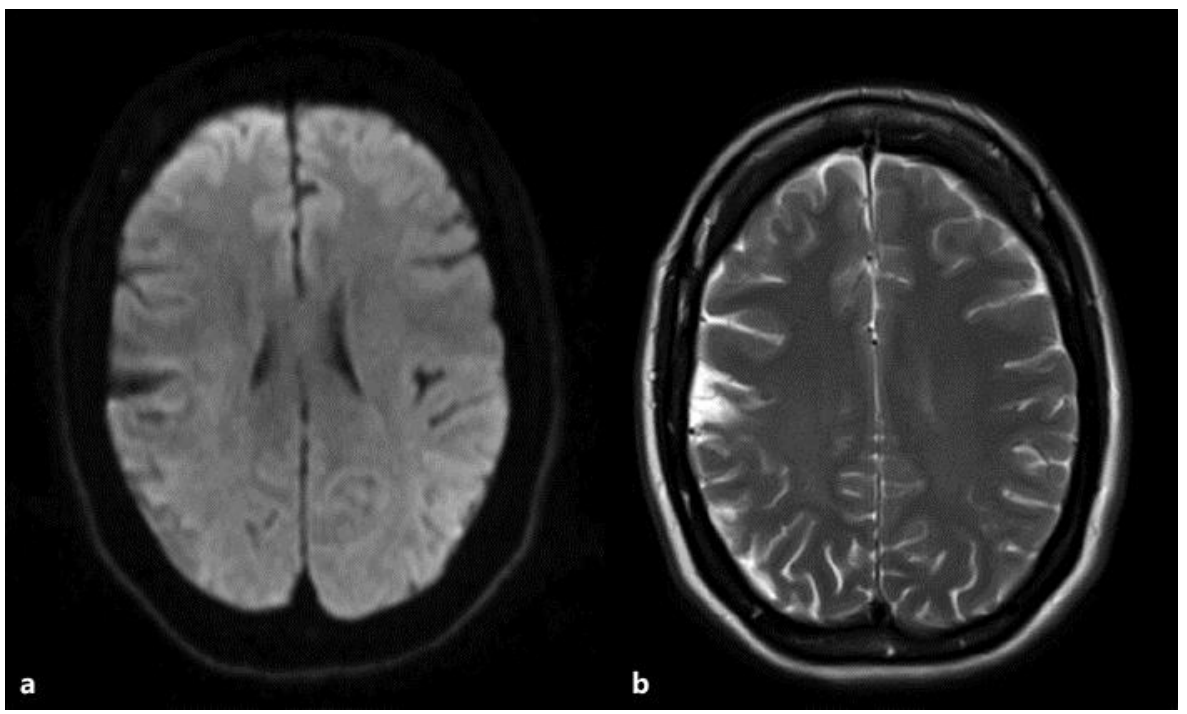

Fig. 3. a MR diffusion 18 days after symptom onset. b MR T2 axial 18 days after symptom onset. 
Rath et al:: Acute Intravenous Calcium Antagonist for Suspected Hemiplegic Migraine A Case Story

Table 1. Elapsed time since symptom onset (T0)

$1 \mathrm{~h} 40 \mathrm{~min}$

$1 \mathrm{~h} 54 \mathrm{~min}$

$2 \mathrm{~h} 11 \mathrm{~min}$

$3 \mathrm{~h} 11 \mathrm{~min}$

$4 \mathrm{~h} 43 \mathrm{~min}$

4 h 53 min

$5 \mathrm{~h} 56 \mathrm{~min}$

18 days

\author{
Admission to Stroke Unit \\ Brain CT with perfusion images \\ Start of rtPA treatment \\ End of rtPA treatment \\ Verapamil infusion \\ Clinical remission \\ Brain MRI \\ Brain MRI
}

